\title{
Clinical Impact of Amino Acid PET in Gliomas
}

$\mathbf{W}_{\text {it }}$ tumors of the central nervousystem are a heterogeneous group, with meningiomas $(35.5 \%)$ and gliomas (30\%) being the most common (1). Although $97 \%$ of meningiomas are benign, $54 \%$ of gliomas are highly malignant glioblastomas of World Health Organization (WHO) grade IV. Survival rates are $35.7 \%$ at $1 \mathrm{y}$ and $4 \%-7 \%$ at $5 \mathrm{y}$ for glioblastoma, $60 \%-80 \%$ at $1 \mathrm{y}$ and $26 \%-46 \%$ at $5 \mathrm{y}$ for astrocytomas and oligodendrogliomas of WHO grade III, and $94 \%$ at $1 \mathrm{y}$ and $67 \%$ at $5 \mathrm{y}$ for astrocytomas and oligodendrogliomas of WHO grade II (2). Additionally, the central nervous system may be invaded by metastases from other malignancies.

Brain tumors create structural lesions whose diagnosis is primarily dependent on imaging with CT and MR. However, it is possible to improve clinical management by using PET to provide physiologic and biochemical information on tumor metabolism, proliferation rate, and invasiveness, as well as to determine the relationship of the tumor to important functional tissue and to monitor the effects of treatment (3).

Imaging of brain tumors with ${ }^{18} \mathrm{~F}-\mathrm{FDG}$ was the first oncologic application of PET. As in other malignancies, glucose consumption is increased in brain tumors, especially in malignant gliomas, but differentiating tumors from normal tissue or nontumorous lesions is often difficult because of the high metabolism in normal cortex. ${ }^{18} \mathrm{~F}$ FDG uptake in low-grade tumors is usually similar to that in normal white matter, and uptake in high-grade tumors can be less than or similar to that in normal gray matter. The sensitivity of detection of lesions is further decreased by the high variance of ${ }^{18} \mathrm{~F}$-FDG uptake and its heterogeneity within a single tumor. Labeled amino acids and their analogs are particularly attractive for imaging brain tumors because of the high uptake in tumor tissue and low uptake in normal brain. This increased amino acid uptake, especially in gliomas, is not a direct measure of protein synthesis or dependent on blood-brain barrier breakdown but rather is related to increased transport mediated by type L amino acid carriers: facilitated transport is upregulated because of the increased transporter expression in tumor vasculature (4). Additionally, the countertransport system A is overexpressed in neoplastic cells and seems to correlate positively with the rate of tumor cell growth (5). Therefore, elevated transport of amino acids not only is a result of increased protein synthesis but also reflects the increased demand by different types of metabolism in the tumor cell.

The most frequently used radiolabeled amino acid is methyl- ${ }^{11} \mathrm{C}$ L-methionine (MET) (6,7). Especially in low-grade gliomas, amino acid uptake is related to prognosis and survival. With regard to tumor extent and infiltration into surrounding tissue, assessment of amino acid

Received May 28, 2014; revision accepted Jun. 23, 2014.

For correspondence or reprints contact: Wolf-Dieter Heiss, Max Planck Institute for Neurological Research, Gleueler Strasse 50, Cologne 50931, Germany.

E-mail: wdh@nf.mpg.de

Published online Jul. 8, 2014.

COPYRIGHT (C) 2014 by the Society of Nuclear Medicine and Molecular Imaging, Inc.

DOI: $10.2967 /$ jnumed.114.142661 uptake is superior to measurement of glucose consumption (8) and to conventional contrast-enhanced MR imaging (9) or MR spectroscopy (10). ${ }^{11} \mathrm{C}$-MET PET detects solid parts of tumors as well as the infiltration zone with high sensitivity and specificity $(11)$. Because ${ }^{11} \mathrm{C}$ labeled tracers can be used only in centers with an onsite cyclotron, amino acids were recently labeled with ${ }^{18} \mathrm{~F}$-fluorine to facilitate wider use. Clinically relevant findings have been obtained mainly with two of them: $O$-(2- ${ }^{18} \mathrm{~F}$-fluoroethyl)-L-tyrosine (FET) and 6- ${ }^{18}$ F-fluoro-L-dopa (FDOPA). ${ }^{18} \mathrm{~F}$-FET and ${ }^{18} \mathrm{~F}$-FDOPA are transported into the brain and tumor but are not further metabolized. Thus, they-in contrast to ${ }^{11} \mathrm{C}$ MET - reflect transport only. Tumor uptake of ${ }^{18} \mathrm{~F}$-FET and ${ }^{18} \mathrm{~F}$ FDOPA is similar to that of ${ }^{11} \mathrm{C}$-MET $(6,7,12,13) .{ }^{18} \mathrm{~F}$-FET PET is well suited for differential diagnosis of primary brain tumors (14) and for differentiation between low- and high-grade gliomas. ${ }^{18}$ F-FET PETalso indicates malignant progression of low-grade gliomas during the course of the disease (15). Uptake of ${ }^{18} \mathrm{~F}$-FET is not dependent on changes in the blood-brain barrier but on cell density (16). Dynamic ${ }^{18} \mathrm{~F}-\mathrm{FET}$ PET may even help to identify high-risk patients (17) and to predict survival (18). In a large study, ${ }^{18}$ F-FDOPA demonstrated excellent visualization of high- and low-grade tumors and was more sensitive and specific than ${ }^{18}$ F-FDG (19). Especially in newly diagnosed tumors, uptake has been shown to be related to proliferation, whereas this correlation has not been observed in recurrent gliomas (20). In astrocytomas, ${ }^{18}$ F-FDOPA PET has detected areas with more actively proliferating cell populations (as proven by biopsy) and permitted targeted radiation (21). ${ }^{18} \mathrm{~F}$-fluoro-L-thymidine (FLT) PET in some instances has been superior to amino acid PET for imaging proliferation in different gliomas and may add significant information about invasiveness, but ${ }^{18} \mathrm{~F}$-FDOPA PET has been found to be superior to ${ }^{18} \mathrm{~F}$-FDG and ${ }^{18} \mathrm{~F}$-FLT in the evaluation of low-grade gliomas (22).

Because of the high cortical background activity, ${ }^{18} \mathrm{~F}-\mathrm{FDG}$ is limited in the detection of residual tumor after therapy. The effects of radiation and chemotherapy can be shown only after a few weeks of treatment, and recurrent tumor or malignant transformation is marked by newly occurring hypermetabolism. Hypermetabolism after radiotherapy, however, can also be mimicked by infiltration of macrophages. With these limitations, ${ }^{18}$ F-FDG PET is not the preferred method to assess therapeutic effects. For this application, amino acid and nucleoid tracers are better suited.

Several studies have suggested that patient outcomes are better when ${ }^{11} \mathrm{C}$-MET or ${ }^{18} \mathrm{~F}$-FET PET is coregistered to MR imaging than when MR imaging is used alone $(23) .{ }^{11} \mathrm{C}-\mathrm{MET}$ PET coregistered to MR imaging has high sensitivity and specificity $(\sim 75 \%)$ for differentiation between recurrent tumor as a sign of treatment failure and necrosis as a sign of success $(24,25)$. Malignant progression in nontreated and treated patients has been detected with high sensitivity and specificity by ${ }^{11} \mathrm{C}$-MET PET. The volume of metabolically active tumor in recurrent glioblastoma multiforme is underestimated by gadolinium-enhanced MR imaging. In one study, the additional information supplied by ${ }^{11} \mathrm{C}$-MET PET changed management in half the cases (26). 
Responses after chemotherapy can be detected by amino acid PET early in the course of disease (27), suggesting that deactivation of amino acid transport is an early sign of response to chemotherapy. ${ }^{18}$ F-FET PET coregistered to MR imaging has been shown to detect the effects of multimodal treatment more sensitively than conventional MR imaging alone, reaching a sensitivity of more than $80 \%$ and a specificity of close to $100 \%$ (28).

A prospective study evaluated the prognostic value of early changes in ${ }^{18} \mathrm{~F}$-FET uptake after postoperative radiochemotherapy in glioblastomas (29). Patients with a more than $10 \%$ decrease in tumorto-brain ratio had significantly longer disease-free survival than patients with stable or increasing tracer uptake. In a study using ${ }^{18} \mathrm{~F}-$ FLT PET, responders to combination therapy could be distinguished from nonresponders: ${ }^{18} \mathrm{~F}$-FLT PET at 2 and 6 wk predicted survival better than did MR imaging (30). A combination of ${ }^{18} \mathrm{~F}-\mathrm{FDOPA}$ and ${ }^{18} \mathrm{~F}$-FLT PET has been shown to further improve prediction of treatment response (31). Multimodal imaging, including various PET and MR imaging modalities, will have a strong impact on the development of new therapeutic strategies (32).

In summary, with the availability of tracers with longer half-lives, molecular imaging has gained broader access to the management of brain tumors, but its utilization is still more limited in brain oncology than in general oncology. Compared with CT or MR imaging, amino acid PET permits more precise demarcation of tumors, better definition of malignancy and prognosis, and earlier detection of recurrences. Additionally, amino acid PET can be used to monitor the effects of treatment and to allow early differentiation between responders and nonresponders. The unique information gained justifies the cost of molecular imaging with PET when used in addition to the established diagnostic procedures (33).

Combination of imaging modalities may be best achieved by hybrid PET/MR, permitting simultaneous assessment of morphologic, physiologic, and molecular parameters (34,35). Integrated PET/MR imaging might become the gold standard for diagnosis of gliomas in the future.

\section{Wolf-Dieter Heiss Max Planck Institute for Neurological Research Cologne, Germany}

\section{REFERENCES}

1. Dolecek TA, Propp JM, Stroup NE, Kruchko C. CBTRUS statistical report: primary brain and central nervous system tumors diagnosed in the United States in 2005-2009. Neuro-oncol. 2012;14(suppl 5):v1-v49.

2. Yang $P$, Wang $Y$, Peng $X$, et al. Management and survival rates in patients with glioma in China (2004-2010): a retrospective study from a single-institution. J Neurooncol. 2013;113:259-266.

3. Heiss W-D, Raab P, Lanfermann H. Multimodality assessment of brain tumors and tumor recurrence. J Nucl Med. 2011;52:1585-1600.

4. Miyagawa T, Oku T, Uehara H, et al. "Facilitated" amino acid transport is upregulated in brain tumors. J Cereb Blood Flow Metab. 1998;18:500-509.

5. Bading JR, Kan-Mitchell J, Conti PS. System A amino acid transport in cultured human tumor cells: implications for tumor imaging with PET. Nucl Med Biol. 1996;23:779-786.

6. Becherer A, Karanikas G, Szabo M, et al. Brain tumour imaging with PET: a comparison between $\left[{ }^{18} \mathrm{~F}\right]$ fluorodopa and $\left[{ }^{11} \mathrm{C}\right]$ methionine. Eur J Nucl Med Mol Imaging. 2003;30:1561-1567.

7. Weber WA, Wester HJ, Grosu AL, et al. O- $\left(2-\left[{ }^{18} \mathrm{~F}\right]\right.$ fluoroethyl $)-\mathrm{L}-$ tyrosine and L[methyl- ${ }^{11} \mathrm{C}$ ]methionine uptake in brain tumours: initial results of a comparative study. Eur J Nucl Med. 2000;27:542-549.

8. Pirotte B, Goldman S, Massager N, et al. Comparison of ${ }^{18} \mathrm{~F}-\mathrm{FDG}$ and ${ }^{11} \mathrm{C}$-methionine for PET-guided stereotactic brain biopsy of gliomas. J Nucl Med. 2004;45:1293-1298.

9. Pauleit D, Floeth F, Hamacher K, et al. O- $\left(2-\left[{ }^{18} \mathrm{~F}\right]\right.$ fluoroethyl $)$-L-tyrosine PET combined with MRI improves the diagnostic assessment of cerebral gliomas. Brain. 2005; 128:678-687.
10. Floeth FW, Pauleit D, Wittsack HJ, et al. Multimodal metabolic imaging of cerebral gliomas: positron emission tomography with $\left[{ }^{18} \mathrm{~F}\right]$ fluoroethyl-Ltyrosine and magnetic resonance spectroscopy. J Neurosurg. 2005;102:318-327.

11. Kracht LW, Miletic H, Busch S, et al. Delineation of brain tumor extent with $\left[{ }^{11} \mathrm{C}\right] \mathrm{L}-\mathrm{methionine}$ positron emission tomography: local comparison with stereotactic histopathology. Clin Cancer Res. 2004;10:7163-7170.

12. Kratochwil C, Combs SE, Leotta K, et al. Intra-individual comparison of ${ }^{18} \mathrm{~F}-\mathrm{FET}$ and ${ }^{18}$ F-DOPA in PET imaging of recurrent brain tumors. Neuro-oncol. 2014;16:434-440.

13. Grosu AL, Astner ST, Riedel E, et al. An interindividual comparison of O-(2$\left[{ }^{18} \mathrm{~F}\right]$ fluoroethyl)-L-tyrosine (FET)- and L-[methyl- $\left.{ }^{11} \mathrm{C}\right]$ methionine (MET)-PET in patients with brain gliomas and metastases. Int J Radiat Oncol Biol Phys. 2011;81:1049-1058.

14. Dunet V, Rossier C, Buck A, Stupp R, Prior JO. Performance of ${ }^{18}$ F-fluoro-ethyltyrosine $\left({ }^{18} \mathrm{~F}\right.$-FET) PET for the differential diagnosis of primary brain tumor: a systematic review and metaanalysis. J Nucl Med. 2012;53:207-214.

15. Galldiks N, Stoffels G, Ruge MI, et al. Role of O-(2- ${ }^{18}$ F-fluoroethyl)-L-tyrosine PET as a diagnostic tool for detection of malignant progression in patients with low-grade glioma. J Nucl Med. 2013;54:2046-2054.

16. Rahm V, Boxheimer L, Bruehlmeier M, et al. Focal changes in diffusivity on apparent diffusion coefficient MR imaging and amino acid uptake on PET do not colocalize in nonenhancing low-grade gliomas. J Nucl Med. 2014;55:546-550.

17. Jansen NL, Suchorska B, Wenter V, et al. Dynamic ${ }^{18}$ F-FET PET in newly diagnosed astrocytic low-grade glioma identifies high-risk patients. J Nucl Med. 2014;55:198-203.

18. Niyazi M, Jansen N, Ganswindt U, et al. Re-irradiation in recurrent malignant glioma: prognostic value of $\left[{ }^{18}\right.$ F]FET-PET. J Neurooncol. 2012;110:389-395.

19. Chen W, Silverman DH, Delaloye S, et al. ${ }^{18}$ F-FDOPA PET imaging of brain tumors: comparison study with ${ }^{18} \mathrm{~F}-\mathrm{FDG}$ PET and evaluation of diagnostic accuracy. J Nucl Med. 2006;47:904-911.

20. Fueger BJ, Czernin J, Cloughesy T, et al. Correlation of $6{ }^{-18} \mathrm{~F}$-fluoro-L-dopa PET uptake with proliferation and tumor grade in newly diagnosed and recurrent gliomas. J Nucl Med. 2010;51:1532-1538.

21. Pafundi DH, Laack NN, Youland RS, et al. Biopsy validation of ${ }^{18} \mathrm{~F}-\mathrm{DOPA}$ PET and biodistribution in gliomas for neurosurgical planning and radiotherapy target delineation: results of a prospective pilot study. Neuro-oncol. 2013;15:1058-1067.

22. Tripathi M, Sharma R, D'Souza M, et al. Comparative evaluation of F-18 FDOPA, F-18 FDG, and F-18 FLT-PET/CT for metabolic imaging of low grade gliomas. Clin Nucl Med. 2009;34:878-883.

23. Pirotte BJ, Levivier M, Goldman S, et al. Positron emission tomography-guided volumetric resection of supratentorial high-grade gliomas: a survival analysis in 66 consecutive patients. Neurosurgery. 2009;64:471-481.

24. Van Laere K, Ceyssens S, Van Calenbergh F, et al. Direct comparison of ${ }^{18} \mathrm{~F}-\mathrm{FDG}$ and ${ }^{11} \mathrm{C}$-methionine PET in suspected recurrence of glioma: sensitivity, inter-observer variability and prognostic value. Eur J Nucl Med Mol Imaging. 2005;32:39-51.

25. Terakawa Y, Tsuyuguchi N, Iwai Y, et al. Diagnostic accuracy of ${ }^{11} \mathrm{C}$-methionine PET for differentiation of recurrent brain tumors from radiation necrosis after radiotherapy. J Nucl Med. 2008;49:694-699.

26. Yamane T, Sakamoto S, Senda M. Clinical impact of ${ }^{11} \mathrm{C}$-methionine PET on expected management of patients with brain neoplasm. Eur J Nucl Med Mol Imaging. 2010;37:685-690.

27. Wyss M, Hofer S, Bruehlmeier M, et al. Early metabolic responses in temozolomide treated low-grade glioma patients. J Neurooncol. 2009;95:87-93.

28. Mehrkens JH, Popperl G, Rachinger W, et al. The positive predictive value of O(2- $\left[{ }^{18} \mathrm{~F}\right]$ fluoroethyl)-L-tyrosine (FET) PET in the diagnosis of a glioma recurrence after multimodal treatment. J Neurooncol. 2008;88:27-35.

29. Galldiks N, Langen KJ, Holy R, et al. Assessment of treatment response in patients with glioblastoma using $\mathrm{O}-\left(2-{ }^{18} \mathrm{~F}\right.$-fluoroethyl)-L-tyrosine PET in comparison to MRI. J Nucl Med. 2012;53:1048-1057.

30. Chen W, Delaloye S, Silverman DH, et al. Predicting treatment response of malignant gliomas to bevacizumab and irinotecan by imaging proliferation with $\left[{ }^{18} \mathrm{~F}\right]$ fluorothymidine positron emission tomography: a pilot study. J Clin Oncol. 2007; $25: 4714-4721$.

31. Harris RJ, Cloughesy TF, Pope WB, et al. ${ }^{18} \mathrm{~F}$-FDOPA and ${ }^{18} \mathrm{~F}-\mathrm{FLT}$ positron emission tomography parametric response maps predict response in recurrent malignant gliomas treated with bevacizumab. Neuro-oncol. 2012;14:1079-1089.

32. Jarzabek MA, Sweeney KJ, Evans RL, et al. Molecular imaging in the development of a novel treatment paradigm for glioblastoma (GBM): an integrated multidisciplinary commentary. Drug Discov Today. 2013;18:1052-1066.

33. Heinzel A, Stock S, Langen KJ, Muller D. Cost-effectiveness analysis of amino acid PET-guided surgery for supratentorial high-grade gliomas. J Nucl Med. 2012;53:552-558.

34. Catana C, Drzezga A, Heiss WD, Rosen BR. PET/MRI for neurologic applications. J Nucl Med. 2012;53:1916-1925.

35. Bisdas S, Ritz R, Bender B, et al. Metabolic mapping of gliomas using hybrid MR-PET imaging: feasibility of the method and spatial distribution of metabolic changes. Invest Radiol. 2013;48:295-301. 